\title{
IMMUNOLOCALIZATION OF HEXOSE TRANSPORTERS IN OSTRICHES' INTESTINAL EPITHELIAL CELLS DURING THEIR FIRST POSTNATAL WEEK
}

\author{
Piret Hussar ${ }^{1}$, Tõnu Järveots ${ }^{2}$, Ilmārs DŪrītis ${ }^{3}$ \\ ${ }^{1}$ Faculty of Medicine, University of Tartu, Tartu, Estonia \\ ${ }^{2}$ Institute of Veterinary Medicine and Animal Sciences, \\ Estonian University of Life Sciences, Tartu, Estonia \\ ${ }^{3}$ Faculty of Veterinary Medicine, Latvian University of Agriculture, Jelgava, Latvia
}

\begin{abstract}
Although hexoses glucose and fructose serve as important energy sources of food, up to now, there is little information about hexose transporters in birds' intestinal epithelium during their first postnatal week. The aim of the investigation was to carry out an immunohistochemical study of integral membrane proteins glucose transporter-2 and -5 (GLUT-2 and GLUT-5) on intestinal epithelial cells of ostrich chicks during their first postnatal week.

The material from duodenum and ileum was collected from 9 female ostriches (Struthio camelus var. Domesticus) divided into three age groups, three birds in each group: chicks immediately after hatching, 3-day-old ostriches and 7-day-old chicks. The material was fixed in $10 \%$ formalin, embedded into paraffin, slices $7 \mu \mathrm{m}$ thick were cut followed by immunohistochemical staining with polyclonal primary antibodies Rabbit antiGLUT-2 and Rabbit anti-GLUT-5, carried out according to the manufacturer's guidelines (IHC kit, Abcam, UK).

Immunohistochemical localization of GLUT-2 and -5 in the intestinal epithelial cells in ostriches of different age groups was determined. In the groups of chicks after hatching and 3-day-old ostriches, enterocytes in duodenal epithelium were mostly unstained and goblet cells stained weakly for both antibodies. Weak staining of enterocytes and goblet cells was also noted in the ileal epithelium of the chick after hatching. Moderate staining of goblet cells was noted in the 3-day-old chicks' ileal epithelium. In 7-day-old ostriches, the expression of both antibodies was weak in duodenal but moderate in ileal epithelial cells.
\end{abstract}


The pattern of immunohistochemical expression of GLUT-2 and GLUT-5 in ostriches' intestinal epithelial cells confirms our hypothesis that the intestinal tract of ostriches after hatching is not yet entirely capable of transportation of hexoses and showed that it is completing gradually during the first postnatal week.

Keywords: hexose transporters; ostriches; intestinal epithelium; first postnatal week

\section{INTRODUCTION}

Although carbohydrates are the main energy source of food, the information about the localization of hexose transporters in different species is very valuable [12]. According to the farmers' observations, it is not advisable to start the feeding of ostrich chicks earlier than on the third or fourth day after hatching; starting of feeding earlier increases ostrich chicks' mortality [5]. The optimal time of the first feeding of ostrich chicks mainly depends on how well developed and functioning the digestive tract is $[6,7,10]$. As until now there is little information about glucose transporters in birds intestinal epithelium in their first postnatal week, the aim of the investigation was to carry out an immunohistochemical study of the integral membrane proteins glucose transporter- 2 and -5 (GLUT-2 and GLUT-5) that facilitate the transport of hexoses across epithelial cell layers on intestinal epithelial cells of ostrich chicks during their first postnatal week.

\section{MATERIAL AND METHODS}

The material from duodenum and terminal part of ileum was collected from 9 female ostrich chicks (Struthio camelus var. Domesticus) raised on an ostrich farm in Latvia. The ostriches were divided into three age groups, three birds in each group: chicks immediately after hatching, 3-day-old ostriches and 7-dayold chick. Commercial ostrich chicks' feed - Strus Premium-Strus 1 and water were available ad libitum. To minimize pain before euthanasia, anaesthesia by $0.5 \mathrm{ml}$ of $10 \%$ ketamine and $0.5 \mathrm{ml}$ of $2 \%$ xylazine solution intramuscularly was carried out, followed by $0.5 \mathrm{ml}$ of $20 \%$ pentobarbital intracardiac injection.

The material $0.5-1.0 \mathrm{~cm}$ in diameter was fixed in $10 \%$ formalin $(48 \mathrm{~h}$ at room temperature), dehydrated in a tissue processor (TISSUE-TEK II) and embedded into paraffin according to the standardized tissue histological 
procedure [4] (Carson). Thereafter, $7 \mu \mathrm{m}$ thick slices were cut (microtome Microm HM360), floated on Poly-L-Lysine coated slides (O. Kindler GmbH, Freiburg, Germany), deparaffinized with xylene and rehydrated in a graded series of ethanol followed by immunohistochemical staining with polyclonal primary antibodies Rabbit anti-GLUT-2 and Rabbit anti-GLUT-5 in 1/1000 dilution for $30 \mathrm{~min}$ at $37^{\circ} \mathrm{C}$ according to the manufacturer's guidelines (IHC kit, Abcam, UK). Biotinylated secondary antibody and streptavidin-conjugated peroxidase were used for detection using DAB as chromogen. Nuclei were counterstained with Harris Hematoxylin. Negative controls contained antibody diluent (Dako, S0809) instead of primary antibodies. Photos of the slides were taken by the microscope Zeiss Axioplan-2 Imaging (Germany) and saved to the computer for analysing by visual control using the camera (AxioCam HRc, Germany) connected to the microscope.

The experiments were carried out in accordance with the Guidelines laid down by the European Communities Council Directive of 24 November 1986 (86/609/EEC), and the Ethical Committee of Latvian University of Agriculture has approved the experiments (protocol number 2014/2).

\section{RESULTS}

The obtained results showed the immunohistochemical expression of GLUT-2 and -5 in the duodenal and ileal epithelial cells of ostriches in different age groups (Table 1).

Table 1. The expression of GLUT-2 and GLUT-5 in duodenal and ileal epithelium of ostriches during their first postnatal week

\begin{tabular}{l|ccc|ccc}
\multirow{2}{*}{$\begin{array}{l}\text { Anti- } \\
\text { body }\end{array}$} & $\begin{array}{c}\text { After } \\
\text { hatching }\end{array}$ & 3 days & 7 days & \multicolumn{3}{c}{ Terminal zone of ileum } \\
\cline { 2 - 7 } hatching & 3 days & 7 days \\
\hline GLUT-2 & weak & weak & weak & weak & weak/moderate & moderate \\
\hline GLUT-5 & weak & weak & weak/moderate & weak & weak/moderate & moderate \\
\hline
\end{tabular}

In the groups of chick after hatching and 3-day-old ostriches, enterocytes in duodenal epithelium were mostly unstained, and goblet cells were mostly stained weakly for both antibodies; some enterocytes were weakly stained in 3-day-old ostriches' upper parts of the intestinal villi (Fig. 1-2). 


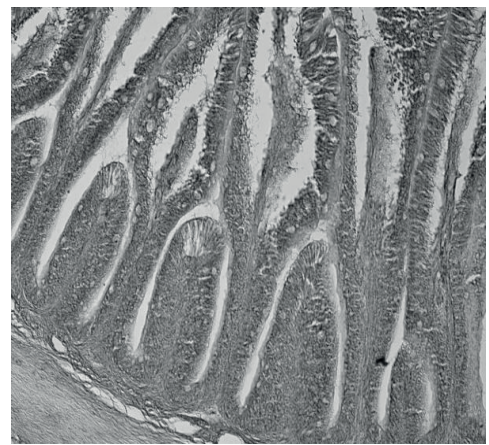

Figure 1. Weak staining for GLUT-2 in epithelium of duodenal mucosa of ostriches after hatching. $200 \times$.

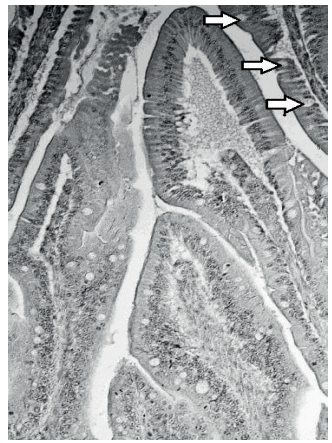

Figure 2. Weak staining for GLUT-5 in epithelium of duodenal mucosa of 3-day-old ostriches. Note the unstained goblet cells (arrows) in the epithelium. $200 x$.

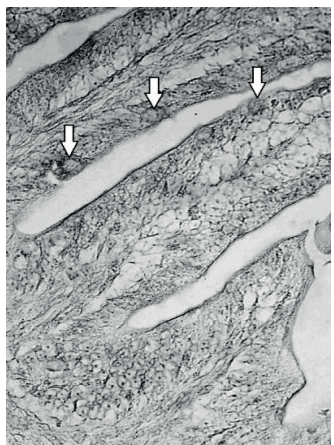

Figure 3. Moderate staining of goblet cells (arrows) in 3-day-old chicks' ileal epithelium. GLUT-5. 400x.

Weak staining of enterocytes and goblet cells was also noted in the ileal epithelium of the chicks after hatching. Some moderate staining of goblet cells and brush border membranes was noted in 3-day-old chicks' ileal epithelium (Fig. 3).

In 7-day-old ostriches, the expression of both antibodies was mostly weak in duodenal but moderate in ileal epithelial cells (Fig. 4-5).

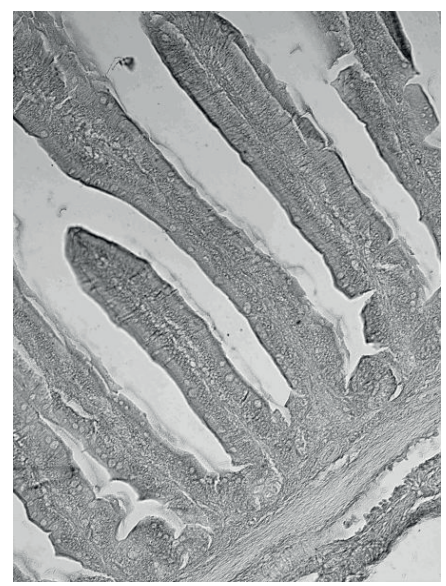

Figure 4. Weak staining for GLUT-2 in epithelial cells of the duodenal villi of 7-day-old ostriches. 200x.

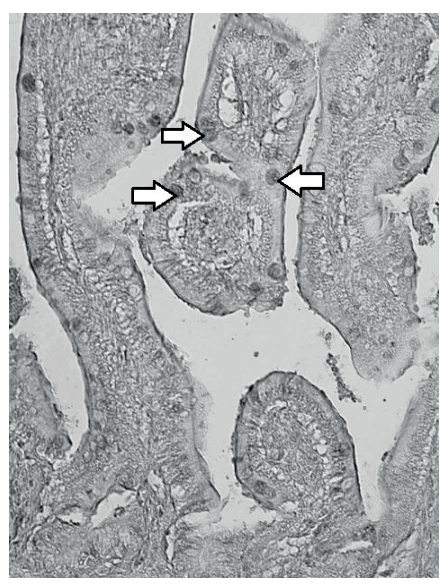

Figure 5. Moderate staining of the epithelial cells (arrows) in the 7-day-old chicks' ileal epithelium. GLUT-5. 200×. 


\section{DISCUSSION}

Hexoses are a key energy source for most living cells $[12,17]$. The uptake of hexoses into intestinal enterocytes is mediated by $\mathrm{Na}+$ /glucose co-transporter (SGLT) and the facilitated-diffusion glucose transporters (GLUT) [20]. According to the notes in literature avians express the majority of GLUT members [3], but hexoses transport in birds occurs predominately by passive transport [1, $13,15,20]$. GLUT5 is primarily a fructose transporter located on the apical membrane of intestinal cells of the small intestine $[16,17]$. GLUT-2 is expressed in the basolateral membranes of intestinal epithelial cells and acts as a highcapacity transport system that allows the uninhibited flux of glucose into or out of the cells [16]. GLUT-2 which enables passive movement of hexoses across cell membranes is found also in apical parts of enterocytes [14].

According to literature, ostrich chicks' mortality on farms until 28 days after hatching is very high (about 46\%) [5]. Although research on the gastrointestinal system at early periods of ontogenesis of ostrich chicks has been carried out quite intensively $[2,7,11,18,19]$, the transport of hexoses in ostriches' intestinal epithelium has barely been studied. In previous studies, we have shown temporospatial differences in the pattern of hexose transporters in different bird species as well the differences of the staining intensities of GLUT-2 and GLUT-5 in the intestinal epithelial cells in ostrich chicks of different ages showing the weak staining for both antibodies in chick after hatching and intense staining of the 30-day-old ostriches' epithelial cells $[8,9]$. Our previous studies have raised the question about the activation time of hexose transporters in ostriches' intestinal epithelial cells.

The revealed pattern of immunohistochemical expression of GLUT-2 and GLUT-5 in ostriches' intestinal epithelial cells in the present study confirms our hypothesis that the gastrointestinal tract of ostriches is not yet entirely capable of transportation of hexoses immediately after hatching and showed that the transportation is completing gradually during the first postnatal week.

\section{ACKNOWLEDGEMENTS}

The authors wish to thank Mrs. Mare Tamm and Ms. Daria Antoshkina for their contributions to the paper. 


\section{REFERENCES}

1. Barone S., Fussell S.L., Singh A.K., et al. (2009). S1c2a5 (Glut5) is essential for the absorption of fructose in the intestine and generation of fructoseinduced hypertension. J Biol Chem, 284, 8, 5056-5066.

https://doi.org/10.1074/jbc.M808128200

2. Bezuidenhout, A.J., Van Aswegen, G. (2011). A light microscopic and immunohistochemical study of the gastrointestinal tract of the ostrich (Struthio Camelus L.). Onderstepoort J Vet Res, 57, 37-48.

3. Byers M.S., Howard C., Wang X. (2017). Avian and Mammalian Facilitative Glucose Transporters. J Microarrays, 6, 2, 7. https://doi.org/10.3390/microarrays6020007

4. Carson, F.L. (1997). Histotechnology. Chicago, IL: ASCP Press.

5. Cloete S.W.P., Lambrechts H., Punt K., Brand Z. (2001). Factors related to high levels of ostrich chick mortality from hatching to 90 days of age in an intensive rearing system. JSAVA, 72, 4, 197-202. https://doi.org/10.4102/jsava.v72i4.652

6. Cooper R.G., Mahrose K.M. (2004). Anatomy and physiology of the gastrointestinal tract and growth curves of the ostrich (Struthio camelus). Animal Science Journal, 75, 6, 491-498. https://doi.org/10.1111/j.1740-0929.2004.00218.x

7. Duritis I., Mugurevics A. (2011). Morphometric parameters of the small and large intestine of the ostrich (Struthio Camelus Var. Domesticus) from day 38 of embryonic development to the age of 60 days. LLU Raksti, 26, 321, 84-93.

8. Hussar P., Kaerner M., Duritis I., Plivca A., Pendovski L., Jaerveots T., Popovska-Percinic F. (2017). Temporospatial study of hexose transporters and mucin in the epithelial cells of chicken (Gallus gallus domesticus) small intestine. Pol J Vet Sci, 20, 4, 627-633.

9. Hussar P., Kärner M., Järveots T., Pendovski L., Duritis I., Popovska-Percinic F. (2016). Comparative study of glucose transporters GLUT-2 and GLUT-5 in ostriches gastrointestinal tract. Mac Vet Rev, 39, 2, 225-231. https://doi.org/10.1515/macvetrev-2016-0089

10. Iji P.A., van der Walt J.G., Brand T.S., Boomker E.A., Booyse D. (2003). Development of the digestive tract in the ostrich (Struthio camelus). Archives of Animal Nutrition, 57, 3, 217-228. https://doi.org/10.1080/0003942031000136648

11. Illanes J., Fertilio B., Quijada M., Leyton V.A. (2006). Histologic description of the annexed glands from the ostrich digestive system (Struthio camelus var. domesticus). Int J Morphol, 24, 3, 297-302. https://doi.org/10.4067/S0717-95022006000400001

12. Jequier E. (1994). Carbohydrates as a source of energy. Am J Clin Nutr, 59, 3, 682S-685S. https://doi.org/10.1093/ajcn/59.3.682S

13. Karasov W.H., Cork S.J. (1994). Glucose absorption by a nectarivorous bird: the passive pathway is paramount. Am J Physiol, 267, 1, G18-26.

https://doi.org/10.1152/ajpgi.1994.267.1.G18 
14. Kellett G.L., Brot-Laroche E., Mace O.J., Leturque A. (2008). Sugar absorption in the intestine: the role of GLUT2. J Annual Review of Nutrition, 28, 35-54. https://doi.org/10.1146/annurev.nutr.28.061807.155518

15. Kenneth C. Welch Jr., Allalou A., Sehgal P., Cheng J., Ashok A. (2013). Glucose Transporter Expression in an Avian Nectarivore: The Ruby-Throated Hummingbird (Archilochus colubris). J ProS One, 8, 10, e77003. https://doi.org/10.1371/journal.pone.0077003

16. Mueckler M. (1994). Facilitative glucose transporters. The FEBS Journal, 219, 3, 713-725. https://doi.org/10.1007/978-3-642-79502-2_4

17. Navale A.M., Archana N.P. (2016). Glucose transporters: physiological and pathological roles. Biophys Rev, 8, 1, 5-9. https://doi.org/10.1007/s12551-015-0186-2

18. Noy Y., Sklan D. (1995). Digestion and absorption in the young chick. Poultry Science, 74, 366-373. https://doi.org/10.3382/ps.0740366

19. O’Malley B. (2005). Clinical Anatomy and Physiology of Exotic Species. Elsevier. Netherlands.

20. Uldry M., Thorens, B. (2004). The SLC2 family of facilitated hexose and polyol transporters. Pflügers Arch, 447, 480-489.

https://doi.org/10.1007/s00424-003-1085-0

\section{Address for correspondence:}

Piret Hussar, M.D., D.M.Sc

Chair of Histology and Embryology, Department of Anatomy

Institute of Biomedicine and Translational Medicine, Faculty of Medicine

University of Tartu, Ravila 19, Tartu 50411, Estonia

E-mail: piretut@gmail.com 